\title{
Assessing Factors for Occurrence of Road Accidents in Tanzania Using Panel Data Analysis: Road Safety Perspective
}

\author{
Ndume Vitalis ${ }^{1}$, Angela-Aida Karugila Runyoro ${ }^{2}$, Majige Selemani ${ }^{3}$ \\ ${ }^{1}$ Dar es Salaam Institute of Technology, Dar es Salaam, Tanzania \\ ${ }^{2}$ National Institute of Transport, Dar es Salaam, Tanzania \\ ${ }^{3}$ Bank of Tanzania, Dar es Salaam, Tanzania \\ Email: ^ndumev@gmail.com
}

How to cite this paper: Vitalis, N., Runyoro, A.-A.K. and Selemani, M. (2022) Assessing Factors for Occurrence of Road Accidents in Tanzania Using Panel Data Analysis: Road Safety Perspective. Journal of Transportation Technologies, 12, 123-136. https://doi.org/10.4236/jtts.2022.121008

Received: December 21, 2021

Accepted: January 25, 2022

Published: January 28, 2022

Copyright (C) 2022 by author(s) and Scientific Research Publishing Inc. This work is licensed under the Creative Commons Attribution International License (CC BY 4.0).

http://creativecommons.org/licenses/by/4.0/

\begin{abstract}
This study assessed critical factors for road traffic accidents and associated mitigation to reduce the accidents by the year 2030. The study was guided by research questions, what are the major causatives of road accidents and how to mitigate the problem. The study used secondary data collected from the repository database of traffic police at the division of Tanzania Road Safety Squad. Data were collected at the events of accident occurrences and reported annually by regions. Panel data analysis was used to allow for controlling variables which cannot be observed over time and across areas such as regions. Pooled Poisson model, fixed effect and random effect Poisson model was applied to assess factors for road traffic accidents. Fixed effect model was the best model with a reasonably good fit. Results indicated that all predictors are significant under fixed effect Poisson model with a p-value less than 0.05 but Passengers and Railway crossing road was found insignificant and dropped in the final model. Laws and regulatory frameworks should be formulated and enforced promptly for Tanzania may reach the target of $2^{\text {nd }}$ decade of action for roads safety 2021-2030.
\end{abstract}

\section{Keywords}

Road Accidents, Panel Data Analysis, Fatal Accidents, Pedestrian Crossing, Dangerous Driving, Reckless Driving

\section{Introduction}

The $2^{\text {nd }}$ decade of action for roads safety 2021-2030 calls for all countries to achieve at least a 50 percent reduction of road deaths and injuries by 2030. This 
is a global performance targeted agreed by the member of state to achieve. The World Health ranking report published in 2018 indicated that about 50 percent of deaths globally are caused by fatal road accidents. The Report highlights that road traffic injuries are now the leading killer of people aged between 5 - 29 years. Every day, almost 3700 people are killed globally in road traffic crashes involving cars, buses, motorcycles, bicycles, trucks, or pedestrians [1]. High proportional burden is borne by pedestrians, cyclists and motorcyclists, in particular those living in developing countries [1].

Road traffic accidents are the major cause of deaths and injuries from road vehicle crashes and the growing public health epidemic [2]. Road accident does not only kill people but it is a disaster that adversely affects people, property and environment. Economically, families are hardest hit by both direct medical and indirect costs such as lost wages that result from these injuries. At the national level, road traffic injuries lead to considerable financial costs, particularly in developing countries [3]. Based on these effects, achieving a reduction of road deaths and injuries by 2030, required more control measures on causes of road accidents to be effective [4].

Globally, several studies have been done on causes of the traffic road accidents. For instance, a study on the causes of road accidents was conducted in India and developed a dynamics model for reducing the severity of road accidents by considering human, road, vehicle and environmental factors [5]. It found that human factors were significant and accounted for $95 \%$ of all road traffic accidents. Another study formulated a multiple regression model that analyzed the factors that lead to motorcycle accidents in Kilimanjaro and Arusha regions [6]. The results showed that the number of motorcycle accidents in both Arusha and Kilimanjaro regions had a strong relationship with the experience of drivers, tarmac road, and personal status. Likewise, the study on modelling road traffic accidents was conducted using a logarithmic-linear regression to determine the main factors contributing to road traffic accidents in Turkey [7]. They found that the main factors contributing to road traffic accidents in Turkey were road defects, vehicle defects, passenger errors, driver defects and pedestrian errors, among general factors, driver defects had highest effects, while road defects had the lowest effects on road traffic accidents.

Expansion of road infrastructure and economic growth has been a significant increase in transportation equipment [8]. This increase has not been in line with road safety literacy and training among road users. There have been noted noncompliance practices especially with traffic rules and regulations among drivers and other road users [6]. This situation has resulted in an increase in traffic offenses and road accidents.

In Tanzania, road traffic accidents have become one of the concerns to most Tanzanians in recent times, about 19,058 road traffic accidents deaths were recorded in 2018 which are 5.24 percent of total deaths [9]. The Government of Tanzania has been taking several measures to reduce the road accidents such as 
driver training, public awareness campaigns, improvement of roads, increasing fines to road traffic accident offenders, setting speed limits, deploying and regular inspection of vehicles by police [10] [11]. As part of the national initiative, Tanzania also implemented program campaign aimed at improving road safety in both urban and school children [2]. However, despite these initiatives, the challenge remains a big threat and burden to Tanzania's economic capital and human resources.

Road accidents increased the burden of expenses to the nation and to the individual particular money used in medical, emergence transport, cost of police and funeral. Therefore the increase in the road traffic accident will have direct or indirect effects on the economy of the country. Understanding the trends and patterns of road traffic accidents can help to predict the need for additional services and resources and guide policy-makers on implementing appropriate and sustainable prevention strategies on a long-term basis. This study used a panel data analysis using Poisson models to assess critical factors affecting road accidents for Tanzania Mainland from 2013 to 2020. The Poisson models are used as standard models for the count data [12]. Understanding critical factors associated with traffic road accidents is important for appropriate planning and control measures against road accidents. Therefore, this study aimed at assessing factors for occurrence of road accidents in Tanzania using panel data analysis.

\section{Methodology}

The study used secondary data collected by traffic police in the division of Tanzania Road Safety Squad from 2013 to 2020 in 30 regions in Tanzania Mailand. These data are panel data collected occasionally as the event accident occur in region and reported annually. Data are collected at district level and compiled up to the regional level for each year. Panel data (also known as longitudinal or crosssectional time-series data) is a dataset in which the behavior of entities is observed across time [13].

The panel data analysis was used to allow for controlling variables which cannot be observed such as variables that change over time but not across areas such as regions in these cases. Two nonlinear panel models were estimated including standard pooled Poisson model, Poisson fixed and random effect that involves all the possible explanatory variables considered in this study. Procedure for eliminating insignificant variables using backward and stepwise methods was undertaken and the most parsimonious model was obtained on the basis of minimum value of AIC. The explanatory variables included in the analysis are described in Table 1.

A Pooled Poisson regression model was employed in this study given nonnegative discrete nature of accident data. The Poisson probability specification is

$$
P\left(y_{i t}\right)=\frac{\epsilon^{\lambda_{x}} \lambda_{i t}^{y_{i t}}}{y_{i t} !}, i=1,2, \cdots, N ; t=1,2, \cdots, T
$$


Table 1. Variables included in the analysis.

\begin{tabular}{|c|c|c|}
\hline Variable & Unit & Descriptions \\
\hline \multicolumn{3}{|r|}{ Outcome/Dependent Variable } \\
\hline Total road accidents & Number & Aggregated total road traffic accidents in each region per year \\
\hline \multicolumn{3}{|r|}{ Explanatory Variables } \\
\hline dangerous driving & Number & Rough driving, driving without observing the driving rules on the roads \\
\hline driver negligence & Number & Careless during driving \\
\hline car defect & Number & Defective motor vehicle \\
\hline fire & Number & Car catching the fire \\
\hline Motor cyclist & Number & Federalist those driving all type of bicycle \\
\hline motorcycle & Number & Wades pikipiki (Motor cycle) Boderboder \\
\hline over speed & Number & High speed \\
\hline livestock collection & Number & Crossing livestock on road carried luggage \\
\hline rumination & Number & Low lamination of the light of street light on the roads \\
\hline roadblocks & Number & temporary structure put across a road to stop traffic \\
\hline bad roads & Number & Road with many spot, patching and rating \\
\hline railway crossing & Number & Intersection of the road and railway crossing \\
\hline overtake & Number & Overtaking at restricted area \\
\hline pedestrian & Number & Careless pedestrians \\
\hline passenger & Number & Pedestrian crossing the roads \\
\hline pulling devices on road & Number & Animal card. Crossing animal area \\
\hline alcohol & Number & Drunker Using alcohol \\
\hline
\end{tabular}

where $y_{i t}$ is the number of road accidents observed in the region I for year $t$ and that $\log \lambda_{i t}=x_{i t}^{\prime} \beta$ [14]. In the Poisson count data model, the assumption of independent observations over individual units and across time still holds true with strong assumptions that $E\left(Y_{i t}\right)=\operatorname{Var}\left(Y_{i t}\right)=\lambda_{i t}$. However, the property for time independence permits a possible weakness of the serial correlation of residuals in the model specification that needs further investigation. Nevertheless, this model is used as a benchmark model:

$$
\begin{aligned}
\log \lambda_{i t}= & \alpha_{i}+\beta_{1} \log \text { Danger }_{i t}+\beta_{2} \log \text { DriverNeg }_{i t}+\beta_{3} \log \text { Cardef }_{i t} \\
& +\cdots+\beta_{N} \log \text { Time }_{i t}+\varepsilon_{i t}
\end{aligned}
$$

where, $\lambda_{i t}$ is the expected number of accidents to occur during year $t$ in region $i$, DangerD is the number of accidents due to dangerous driving, DriverNeg is the number of accident due to driver negligence, Cardef is for car defect, and other variables fire, cyclist, motorcycle, over speed, livestock collection, rumination, road blocks, bad roads, railway crossing, overtake, pedestrian, passenger, pulling devices on road and alcohol while TIME is the time trend to account for the differences in accident occurrence across year and $\alpha_{i}, \beta_{1}, \beta_{2}, \beta_{3}, \beta_{4}, \cdots, \beta_{N}$ are unknown parameters to be estimated. In order to account for differences among 
regions and time, two models were tested: Fixed Poisson and random effects model. The random effects model assumed the individual effects are independent, identically distributed and uncorrelated with the observed effect. This method produces inconsistent estimator that the unobserved individual heterogeneity specific effect is correlated with explanatory variables. In which the fixed effects estimators were more appropriate.

Fixed effects Poisson model: For the panel count data for $i$ region, each region observed a total of $t$ times [15] and. Let $\eta_{i t}$ be the count variable for individual $i$ at time $t$. Then the expected value of $\eta_{i t}$ is linked to regressors by:

$$
\begin{aligned}
E\left(\eta_{i t}\right) & =\hat{\lambda}_{i t}=\exp \left(d_{i}+x_{i t}^{\prime} \beta\right), i=1,2, \cdots, N ; t=1,2, \cdots, T \\
& =\alpha_{i} \hat{\lambda}_{i t}
\end{aligned}
$$

where, $d_{i}$ are region specific dummies, $\alpha_{i}=\mathrm{e}^{d_{i}}$ is the individual specific effect, $X_{i t}$ is a vector of regressors. According to [13] the conditional maximum likelihood method is used to estimate the model parameters As $y_{i t}$ follows the Poisson distribution, the sum of accidents:

$$
\sum_{i=1}^{T} y_{i t}
$$

also follows the Poisson distribution with parameters:

$$
\sum \hat{\lambda}_{i t}=\alpha_{i} \sum \lambda_{i t}
$$

The parameters were estimated by obtaining the joint distribution of $\left(y_{i l}, \ldots\right.$, $\left.y_{i T}\right)$ conditional on their sum [13].

During the analysis, the quality model goodness of fit between the fitted and the observed value $y_{p}$ were measured using various statistics. The suitability of the fitted model, the Akaike Information Criteria (AIC) was used to identify the best model among various model examined. The AIC statistic is given by AIC = $-2[L(\beta)]+2 k$ where $L(\beta)$ is the log-likelihood function of the model evaluated under $\beta$ by using observation and $\mathrm{k}$ is the number of unknown parameters.

The random effect Poisson model is that unlike the fixed effects Poisson model, the variation across entities is assumed to be random and uncorrelated with predictor or independent variables included in the model. The Poisson fixed effect model was considered the best model in this study.

\section{Results and Discussion}

\subsection{Trend Analysis of the Factors for Road Accidents}

There are 15 factors that contribute highly to the road accidents. These factors range from Road design engineering to social-economical activities on the roads. The trends analysis of the roads accidents in Figure 1 shows a tremendous reduction of the accident yearly. The situation was worse in year 2013 and it dropped with gradient to 2015 before it raised up in year 2016. From year 2017 there is linear decrease of roads accidents to 2020. It can be explained that from 2013 to 2015 the use of ICT in monitoring the transportation system 


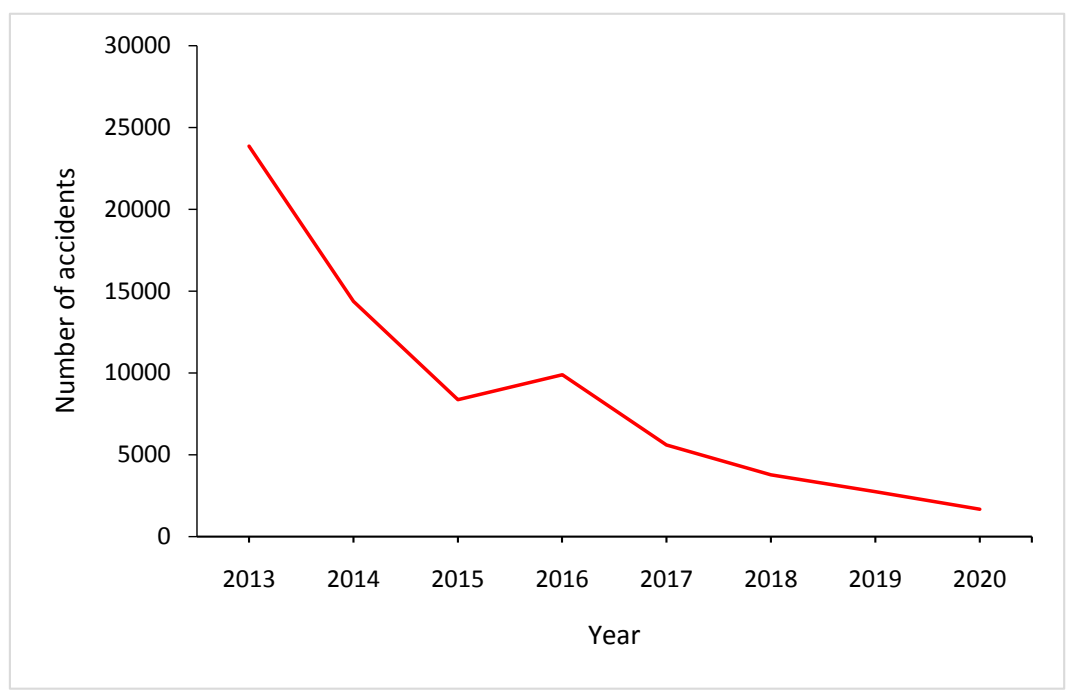

Figure 1. Number of accidents for the period 2013-2020.

was mostly used. These include car tracking system using GPS, most buses were installed and configured with speed governors. Either law enforcement on the speed limit on road was highly applied, the installation of roads signs as well as innovation of traffic light for pedestrian crossing in the cities such as (Mwanza, Simiyu and Manyara and some parts of Dar salaam) has high significant impart in reducing roads accidents. Dar es Saalam Institute of Technology has been part of the manufacturers of such controllers for pedestrian crossing and the Tanzanian Government adopted the technology in year 2018. Notwithstanding use of police camera, installation of video cameras on the roads were also applied to reduce the bad drivers.

The critical factors that contributed to the road accidents are shown in Figure 2. These factors can be discussed into three major groups. The group was categorized according to the percentage causal of road traffic accidents. The group was highly contributors with higher than 10 percent cause of road accidents, the medium with less than 10 to one percent and the low group with less than one percent. The highly contributing factors include negligence of the driver (23.74\%), negligence of motorcyclist (21.1\%) and dangerous driving (12.83\%). The second group of causal for road accidents includes driving with high speed (8.3\%), Defect car (6.6\%), negligence pedestrian (6.12\%), overtaking (6.0\%), cyclist (4.2\%), bad roads (3.7\%), road blocks (3.64\%), vehicle light and street lights (1.58\%). The last group causative of road accidents includes alcohol (0.8\%), railways crossing (Railway crossing and junctions (0.4\%), car catching fire (0.3\%), Animal collection $(0.23 \%)$, negligence of passenger $(0.2 \%)$, pedestrian pulling device over the roads $(0.26 \%)$.

According to traffic police statistics of December 2019, Motorcycle caused about 1338 accidents, 99 injuries and 672 deaths between January and November 2017, a decrease from 2379, to 1998 and then to 820 respectively in the same period was recorded in 2016 [4]. The report claims that at that moment most road 
accident cases reported were caused by Motorcycle and private cars [4].

In order to achieve at least $50 \%$ reduction of road accidents as per $2^{\text {nd }}$ Decade of Action for Road Safety 2021-2030 each factor listed as causative cannot be neglected in a road safety plan.

The distribution of road accidents by regions is presented in Figure 3. The results indicated that Kinondoni has higher cumulated road accidents than any followed by Ilala. Kinondoni, Ilala and Temeke are police region in the Dar es Salaam city. The higher road accidents can be attributed to social economic explanation due to high traffic in the city with unplanned settlement. In the same line population of kinondoni is $1,775,049$, Ilala is $1,220,611$, while Temeke is 1,368,881. Notwithstading the Annula Average Daily Traffic range from 324 outside the city like Tundwi Songani to 104,770 at Kijazi bridge in ubungo njuction.

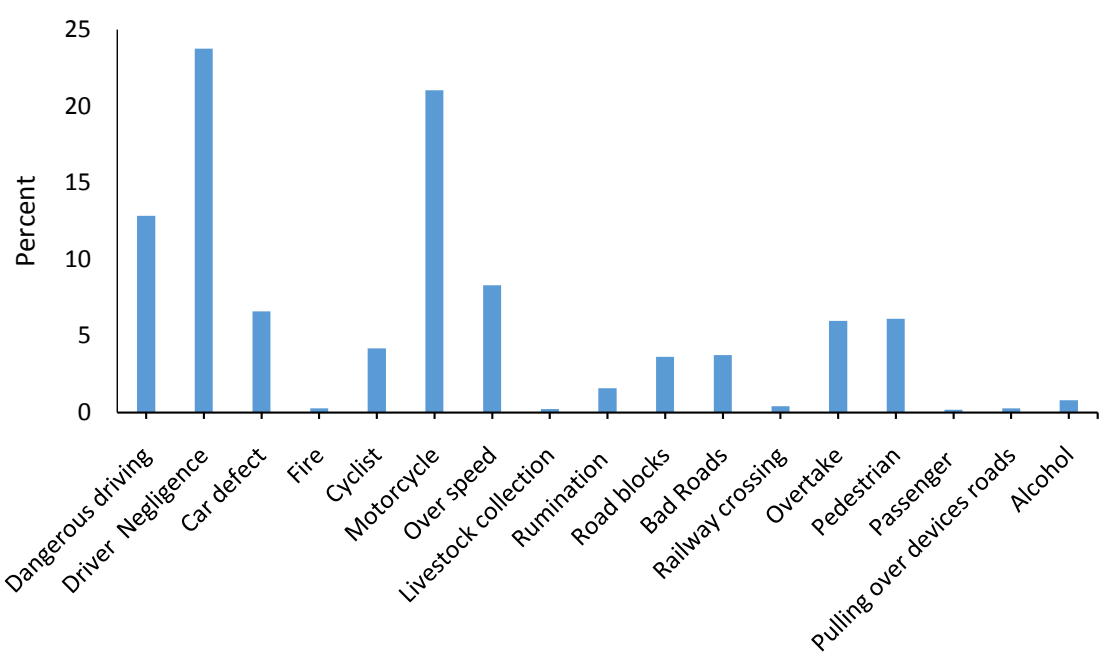

Figure 2. Number of accidents by causative for the period 2013-2020.

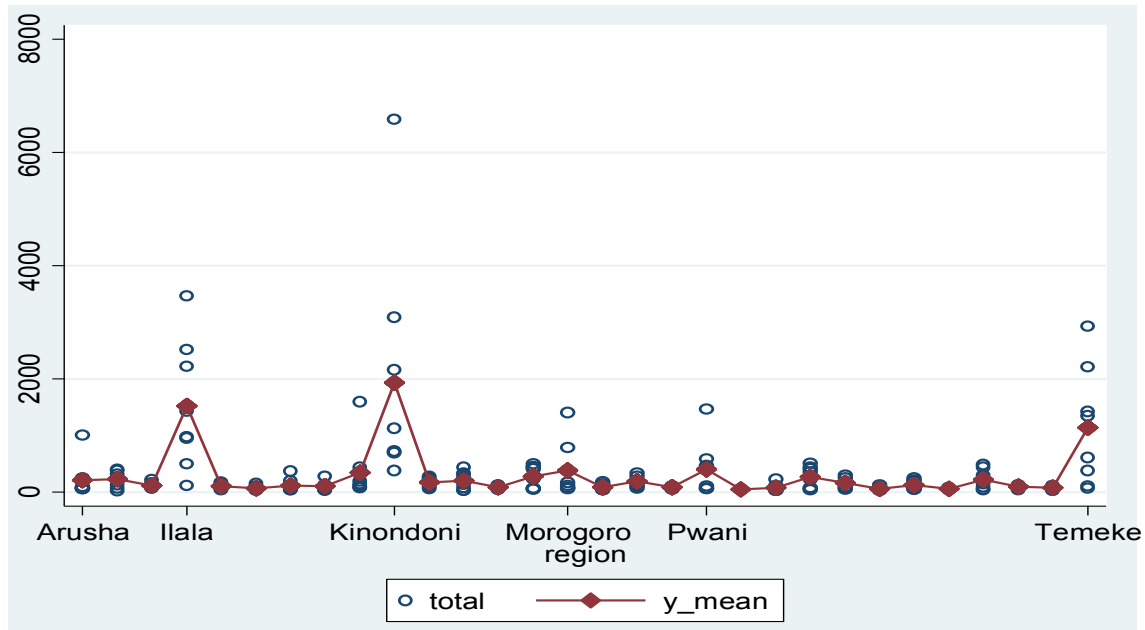

Figure 3. Distribution of accidents by region (Note: y-mean is the average of road accidents for each region from 2013 to 2020). 
It should be noted that Dar es Salam includes Iliala Temeke and Kinondoni followed by Pwani, then Morogoro and Arusha. The road accident for school bus that happens in Arusha 2017 creates an argument that beyond human suffering, road traffic deaths and injuries impose significant economic and financial losses to individuals and to societies. [16] claim that an increase in economic performance is associated with improvement of road transportation infrastructure resulting in the increase motorisation. Therefore, more motorization resulted in more road accidents.

\subsection{Factors Associated with Traffic Road Accidents}

Table 2 presents the coefficients for the final model for Pooled Poisson model, Fixed Effect Poisson model and Random effect Poisson model. The results indicate that Fixed effects Poisson model yields a minimum AIC value of 3860.889 with improved log likelihood value which indicates that the model has a reasonably good of fit compared to random effects and Pooled Poisson model. Passanger and railway crossing were dropped in the model because of insignificant. Results in Table 2 indicate that all predictors are significant since their corresponding $\mathrm{p}$-values are less than 0.05 . Also, the positive coefficient of predictors shows that as a particular predictor increases the likelihood of road traffic accidents increases. That is to say, increasing the factors Dangerous driving, Driver negligence, Car defect, Fire, motor Cyclist, Motorcycle, over speed, bad roads, Overtake, Pedestrian and Alcoholism causes significant increase of road traffic accidents. This implies that the increase in the number of these variables causes an increase in accidents. The positive effect is similar to the findings on the traffic accident study done by [13] [17] [18] analysed factors affect total road accidents. While the Livestock collection, Rumination, Road blocks, pulling over devices roads and time trend have a significant negative effect on the likelihood of road accidents occurrence. This implies that the accident is expected to decrease with an increase of the factors Livestock collection, Rumination, Road blocks, pulling over devices roads and time trend.

Table 3 shows how road accidents can be predicted using explanatory variables by taking exponentials of their estimates. The road traffic accidents with respect to the expalanatory variables are predicted as follows: Dangerous driving with exponential estimate of 1.000713 implies that the number of road accidents next year caused by Dangerous driving will increase by $0.0007124 \%$. Driver negligence with exponential estimate of 1.000411 implies that the number of road accidents next year caused by Driver negligence will increase by $0.0004108 \%$. Car defect with exponential estimate of 1.002083 implies that the number of road accidents next year caused by Car defect will increase by $0.002083 \%$. Fire, motor Cyclist, Motorcycle, over speed, bad roads, Overtake, Pedestrian and Alcoholism with exponential estimate of 1.035705, 1.003834, 1.0001727, 1.00105, 1.001937 implies that the number of road accidents next year caused by these variables will increase by $0.035705,0.003834,0.0001727,0.00105,0.001937$ re- 
spectively (Table 3). Livestock collection, Rumination, Road blocks, pulling over devices roads and time trend with exponential estimate of $0.9686463,0.9890562$, $0.9961342,0.9985291$ and 0.9865246 respectively will decrease the number of road accidents by $0.0318558 \%, 0.0110041 \%, 0.0038733 \%, 0.001472 \%$ and $0.2136283 \%$ respectively. Generally, the results show that fire, alcoholism and overtake contribute most to the occurrence of road accidents.

Table 2. Poisson models parameter estimation.

\begin{tabular}{|c|c|c|c|}
\hline & $\begin{array}{c}\text { Pooled } \\
\text { Poisson Model }\end{array}$ & $\begin{array}{c}\text { Fixed effects } \\
\text { Poisson Model }\end{array}$ & $\begin{array}{l}\text { Random effect } \\
\text { Poisson Model }\end{array}$ \\
\hline Variable & Coefficient & Coefficient & Coefficient \\
\hline Dangerousdriving & $0.000707^{\star *}$ & $0.0007124^{\star \star}$ & $0.000709^{* *}$ \\
\hline DriverNegligence & $0.000408^{\star \star}$ & $0.0004108^{\star *}$ & $0.000407^{\star *}$ \\
\hline Cardefect & $0.0020841^{\star *}$ & $0.0020806^{* *}$ & $0.0020843^{* *}$ \\
\hline Fire & $0.0349749^{* *}$ & $0.0350824^{* *}$ & $0.034981^{* *}$ \\
\hline Cyclist & $0.0038588^{\star *}$ & $0.0038268^{\star *}$ & $0.0038597^{\star *}$ \\
\hline Motorcycle & $0.0010589^{*}$ & $0.0010498^{*}$ & $0.0010579^{*}$ \\
\hline Overspeed & $0.0019193^{\star *}$ & $0.0019352^{\star *}$ & $0.0019183^{* *}$ \\
\hline Livestockcollection & $-0.0319874^{* *}$ & $-0.0318558^{\star *}$ & $-0.0319774^{* *}$ \\
\hline Rumination & $-0.0110285^{\star *}$ & $-0.0110041^{\star *}$ & $-0.0110385^{\star *}$ \\
\hline Roadblocks & $-0.0038819^{* *}$ & $-0.0038733^{\star *}$ & $-0.0038839^{* *}$ \\
\hline BadRoads & $0.0023125^{\star \star}$ & $0.0023114^{\star *}$ & $0.0023325^{\star *}$ \\
\hline Overtake & $0.00462^{\star}$ & $0.0045785^{\star}$ & $0.00452^{*}$ \\
\hline Pedestrian & $-0.0014673^{* *}$ & $-0.001472^{\star *}$ & $-0.0014683^{\star *}$ \\
\hline Pullingoverdevicesroads & $-0.0135791^{\star *}$ & $-0.013567^{\star *}$ & -0.0135801 \\
\hline Alcohol & $0.0107738^{\star \star}$ & $0.0106363^{\star *}$ & $0.0107738^{\star *}$ \\
\hline ttrend & $-0.2130249^{\star}$ & $-0.2136283^{\star *}$ & $-0.2130249^{\star *}$ \\
\hline Constant/Intercept & $5.591488^{\star}$ & & $5.591488^{\star *}$ \\
\hline /lnalpha & $-0.9408104^{* *}$ & & $-0.9408104^{* *}$ \\
\hline alpha & $0.3903114^{*}$ & & $0.3903114^{* *}$ \\
\hline Sample size & 232 & 232 & 232 \\
\hline Group number of regions & 30 & 30 & 30 \\
\hline AIC & 4354.252 & 3860.889 & 4356.232 \\
\hline Log Likelihood (LB) & -2159.126 & -1914.4443 & -2158.126 \\
\hline
\end{tabular}

Note: ${ }^{\star} P$-value $<0.05 ;{ }^{*} P$-value $<0.01 ;$ Panel standard error estimates for the slopes coefficients are/inalpha and alpha; ttrend is time trend. 
Table 3. Road traffic accidents predictors using fixed effects poisson model.

\begin{tabular}{ccc}
\hline Variable & Coefficient & IRR \\
\hline Dangerousdriving & $0.0007124^{* *}$ & 1.000713 \\
DriverNegligence & $0.0004108^{* *}$ & 1.000411 \\
Cardefect & $0.0020806^{* *}$ & 1.002083 \\
Fire & $0.0350824^{* *}$ & 1.035705 \\
Cyclist & $0.0038268^{* *}$ & 1.003834 \\
Motorcycle & $0.0010498^{*}$ & 1.00105 \\
Overspeed & $0.0019352^{* *}$ & 1.001937 \\
Livestockcollection & $-0.0318558^{* *}$ & 0.9686463 \\
Rumination & $-0.0110041^{* *}$ & 0.9890562 \\
Roadblocks & $-0.0038733^{* *}$ & 0.9961342 \\
BadRoads & $0.0023114^{* *}$ & 1.002314 \\
Overtake & $0.0045785^{*}$ & 1.004589 \\
Pedestrian & $-0.001472^{* *}$ & 0.9985291 \\
Pullingoverdevicesroads & $-0.013567^{* *}$ & 0.9865246 \\
Alcohol & $0.0106363^{* *}$ & 1.010693 \\
ttrend & $-0.2136283^{* *}$ & 0.8076485 \\
\hline
\end{tabular}

Note: IRR is incidence Rate Ratio equivalent to exponetial of coefficient, ttrend is time trend.

\subsection{Discussion}

The aims of this study were to assess factors for occurrence of road accidents in Tanzania using panel data analysis in order to inform decision-making and policy-makers for appropriate planning and control measures against road accidents. The number of road traffic accidents drastically reduced from 23,842 in 2013 to 1634 in 2020 probably due to the increased enforcement of traffic regulations, speed limit on road, the installation of roads signs as well as innovation of traffic light for pedestrian crossing and the presence of traffic police officers on the roads as well as intensified road safety campaigns by the national road safety council [19]. Similar study [17] found a decrease in road accidents in Dar es Salaam in three Municipalities of Dar es Salaam Region, Tanzania between 2014 and 2018.

The study assessed factors associated with road traffic accidents in Tanzania and found that Dangerous driving, Driver negligence, Car defect, Fire, Cyclist, Motorcycle, over speed, bad roads, Overtake and Alcoholism have a significant positive effect on the likelihood of road accidents occurrence. These findings are in line with other studies by [4] [20] [21] Furthermore, the livestock collection, Rumination, Road blocks, Pedestrian, pulling devices over roads have a significant negative effect on the likelihood of road accidents occurrence. This was consistent with the results of studies done in Ethiopia [20] [21] [22] [23] which 
found the cause of accidents about $80 \%$ of car accidents were attributed to driver faults among which denying priority for a pedestrian was the leading. To reduce the accidents due to pedestrian crossing a number of pedestrian crossing traffic lights were installed in Mwanza, Simiyu and Manyara.

Most road accidents that occurred due to speed happened in trunk and regional roads where pavement is very good. In such areas, there are high speed cars but also such roads passed along the villages where there is an interaction of pedestrian crossing as well as animal collection. In year 2016 bariadi experienced higher accidents while in year 2018 it had very few accidents.

The traditional approach to reducing accidents at crossing intersections has been handled by road sign or by placing zebra crossing or by speed hampers. Even though these signs are commonly used in enhancement of the pedestrian crossing required the use of engineering technology to enhance effectiveness of roads safety.

Despite installing road safety in some black sport areas Motorcycle known as Bodaboda still remain careless and caused more accidents on crossing section. Since 2013 there is a high increase in Motorcyclist accidents in the country.

Bad roads are all about road geometry. This factor is mostly caused by poor design, absence of road sign, plating big trees nearby the roads, absence of sideways. Bad roads are recorded on road surface or pavement distress which include cracking, patching and potholes, surface deformation, and surface deflect [24]. The author argued that it is not intelligent to roads designer engineers to design good paved road but which kills. Road should save the purpose of transportation communication but also should save people's life. Road width that is too narrow or doesn't comply with standards, sharp curves, steep downhill and uphill, pavement surface damage, and non-illuminated roads are a source of road accidents [24].

Alcoholism is the most dangerous drink that contributes highly to road accidents. Many drivers do use some energy busters which are associated with alcohol. Either some drive long days with no rest. Several studies conclude that not necessary alcohol that may course road death but also dizziness which may be due to lack of good sleeping [25]. The current innovation of alocohl detector explored at Dar es Salaam Institute of Technology can be among the counter measure of alcoholic check before buses take off at any bus stand.

\section{Conclusions and Recommendations}

Based on the findings it is concluded that there is a promising reduction of road accidents between 2015 and 2020. With this reduction, Tanzania can reach the target of reducing road accidents by $50 \%$ by the year 2030 when control measures against factors which contribute more to road traffic accidents are effectively implemented. The study points out the factors leading to road traffic accidents in Tanzania. In general, prevention strategies in Tanzania have been mainly implemented for vehicle occupants, whereas little attention has been paid 
to other road users. However, road accidents caused by Dangerous driving, Driver negligence, Car defect, Fire, Cyclist, Motorcycle, over speed, bad roads, Overtake and Alcoholism remain major public health concerns. Laws and regulatory frameworks should be formulated and enforced promptly to avoid losses caused by the occurrence of the road accidents. Road traffic accidents require a collaborative approach from different sectors so as to address this public health concern in a holistic manner. Pedestrian walkways and pedal-cyclist lanes should be factored in road design. Road safety professionals should be trained, to monitor the magnitude, severity and burden resulting from road traffic accidents in Tanzania.

Based on the conclusion, the study recommends a need to strengthen the technical pillars of the safe system (infrastructure, vehicles, road users, postcrash care and modal shift) in a holistic way. The study also emphasizes the role of road safety governance (priority setting, coordination, financing, human resources as well as knowledge management) in implementation process of road safety. The road safety program led by IRAP should bring and hold everything together through a cycle of continuous improvement. Finally, more research on prediction model for ascertaining the reduction of road accidents to half from 2021-2030 needs to be carried out.

\section{Acknowledgements}

Data for this publication was obtained from repository database of traffic police at the division of Tanzania Road Safety Squad. We appreciate the head of the division for his support. We also acknowledge the support of Dar Es Salaam Institute of Technology.

\section{Conflicts of Interest}

The authors declare no conflicts of interest regarding the publication of this paper.

\section{References}

[1] WHO (2018) Global Status Report on Road Safety 2018.

[2] Peden, M. and Sminkey, L. (2004) World Health Organization Dedicates World Health Day to Road Safety. Injury Prevention, 10, 67-75. https://doi.org/10.1136/ip.2004.005405

[3] WHO (2009) Global Status Report on Road Safety. Geneva World Health Report: Making a Difference. WHO, Geneva.

[4] Sagamiko, T. and Mbare, N. (2020) Modelling Road Traffic Accidents Counts in Tanzania: A Poisson Regression Approach. Tanzania Journal of Science, 16, 456-460.

[5] Kumar, S.N. and Umadevi, G. (2011) Application of System Dynamic Simulation Modelling in Road Safety. 3rd International Conference on Road Safety and Simulation Purdue University Transportation Research Board, Indianapolis, 14-16 September 2011.

[6] Nyakyi, V.P., Kuznetsov, D. and Nkansah-Gyekye, Y. (2014) Validating Regression 
Models to Assess Factors for Motorcycle Accidents in Tanzania. Science Journal of Applied Mathematics and Statistics, 2, 97-101. https://doi.org/10.11648/j.sjams.20140205.12

[7] Tortum, A., et al. (2012) Modelling Traffic Accidents in Turkey Using Regression Analysis. Iğdır University Journal of the Institute of Science and Technology, 2, 69-78.

[8] Prus, P. and Sikora, M. (2021) The Impact of Transport Infrastructure on the Sustainable Development of the Region-Case Study. Agriculture, 11, Article No. 279. https://doi.org/10.3390/agriculture11040279

[9] WHO (2018) Tanzania: Road Traffic Accidents. https://www.worldlifeexpectancy.com/tanzania-road-traffic-accidents

[10] Kimaro, H.C., Mvungi, N.H. and Kundaeli, H. (2016) Challenges in the Management of Road Safetyin Tanzania: The Need for an Integration Framework. Huria: Journal of the Open University of Tanzania, 22, 48-58.

[11] Houben, R. and Snyers, A. (2018) Cryptocurrencies and Blockchain: Legal Context and Implications for Financial Crime, Money Laundering and Tax Evasion. European Parliament.

[12] Cameron, A.C. and Trivedi, P.K. (1986) Econometric Models Based on Count Data: Comparisons and Applications of Some Estimators and Tests. Journal of Applied Econometrics, 1, 29-53. https://doi.org/10.1002/jae.3950010104

[13] Yaacob, W.F.W., Lazim, M.A. and Wah, Y.B. (2011) Applying Fixed Effects Panel Count Model to Examine Road Accident Occurrence. Journal of Applied Sciences, 11, 1185-1191. https://doi.org/10.3923/jas.2011.1185.1191

[14] Cameron, A.C. and Trivedi, P.K. (2005) Microeconometrics: Methods and Applications. Cambridge University Press, Cambridge. https://doi.org/10.1017/CBO9780511811241

[15] Sapra, S. (2005) A Regression Error Specification Test (RESET) for Generalized Linear Models. Economics Bulletin, 3, 1-6.

[16] Vol, H.J. (2018) Socio-Economic Consequences of Road Traffic Accidents to the Victims and their Families in Dar es Salaam Tanzania. Huria: Journal of the Open University of Tanzania, 25, 181-197.

[17] Aga, M.A., Woldeamanuel, B.T. and Tadesse, M. (2021) Statistical Modeling of Numbers of Human Deaths per Road Traffic Accident in the Oromia Region, Ethiopia. PLoS ONE, 16, e0251492. https://doi.org/10.1371/journal.pone.0251492

[18] Geleta, D.K., Adem, H.A., Kumsa, F.A., Demena, M. and Gobena, T. (2020) Road Traffic Accidents Fatality and Associated Factors in Southwest Shoa, Central Ethiopia. East African Journal of Health and Biomedical Sciences, 4, 35-46.

[19] Asefa, F., Assefa, D. and Tesfaye, G. (2014) Magnitude of, Trends in, and Associated Factors of Road Traffic Collision in Central Ethiopia. BMC Public Health, 14, Article No. 1072.

[20] Fenta, H.M. and Workie, D.L. (2014) Analysis of Factors that Affect Road Traffic Accidents in Bahir Dar City, North Western Ethiopia. Science Journal of Applied Mathematics and Statistics, 2, 91-96, https://doi.org/10.11648/j.sjams.20140205.11

[21] Abbafati, C., et al. (2020) Global Burden of 369 Diseases and Injuries in 204 Countries and Territories, 1990-2019: A Systematic Analysis for the Global Burden of Disease Study 2019. The Lancet, 396, 1204-1222. https://doi.org/10.1016/S0140-6736(20)30925-9

[22] Skyving, M., Forsman, Å., Dukic Willstrand, T., Laflamme, L. and Möller, J. (2021) Medical Impairment and Road Traffic Crashes among Older Drivers in Sweden-A 
National, Population-Based, Case-Control Study. Accident Analysis and Prevention, 163, Article ID: 106434. https://doi.org/10.1016/j.aap.2021.106434

[23] Croskerry, P. (2010) To Err Is Human-and Let's Not Forget It. Canadian Medical Association Journal, 182, 524. https://doi.org/10.1503/cmaj.100270

[24] IRAP (2019) EuroRAP Portugal: Technical Report.

[25] Jain, A., Gupta, A. and Rastogi, R. (2014) Pedestrian Crossing Behaviour Analysis at Intersections. International Journal of Traffic and Transportation Engineering, 4, 103-116. https://doi.org/10.7708/ijtte.2014.4(1).08 